\title{
Observations of defect structure evolution in proton and Ni ion irradiated Ni-Cr binary alloys
} \author{
Taheri $^{\mathrm{b}}$, Kumar Sridharan ${ }^{\mathrm{a}}$ \\ ${ }^{a}$ University of Wisconsin-Madison, 1415 Engineering Drive, Madison, WI 53706 \\ ${ }^{b}$ Drexel University, 3141 Chestnut Street, Philadelphia, PA 19104 \\ ${ }^{c}$ SKC•CEN Belgian Nuclear Research Centre, Boeretang 200, B-2400 Mol, Belgium \\ ${ }^{d}$ Sandia National Laboratories, PO Box 5800, Albuquerque, NM 87185
}

Samuel A. Briggs ${ }^{\mathrm{a}, *}$, Christopher M. Barr ${ }^{\mathrm{b}}$, Janne Pakarinen ${ }^{\mathrm{a}, \mathrm{c}}$, Mahmood Mamivand $^{\mathrm{a}}$, Khalid Hattar ${ }^{\mathrm{d}}$, Dane D. Morgan ${ }^{\mathrm{a}}$, Mitra

\begin{abstract}
Two binary Ni-Cr model alloys with $5 \mathrm{wt} . \% \mathrm{Cr}$ and $18 \mathrm{wt} . \% \mathrm{Cr}$ were irradiated using $2 \mathrm{MeV}$ protons at 400 and $500{ }^{\circ} \mathrm{C}$ and $20 \mathrm{MeV} \mathrm{Ni}^{4+}$ ions at $500{ }^{\circ} \mathrm{C}$ to investigate microstructural evolution as a function of composition, irradiation temperature, and irradiating ion species. Transmission electron microscopy (TEM) was applied to study irradiation-induced void and faulted Frank loops microstructures. Irradiations at $500{ }^{\circ} \mathrm{C}$ were shown to generate decreased densities of larger defects, likely due to increased barriers to defect nucleation as compared to $400{ }^{\circ} \mathrm{C}$ irradiations. Heavy ion irradiation resulted in a larger density of smaller voids when compared to proton irradiations, indicating in-cascade clustering of point defects. Cluster dynamics simulations were in good agreement with the experimental findings, suggesting that increases in Cr content lead to an increase in interstitial binding energy, leading to higher densities of smaller dislocation loops in the $\mathrm{Ni}-18 \mathrm{Cr}$ alloy as compared to the $\mathrm{Ni}-5 \mathrm{Cr}$ alloy.
\end{abstract}

Keywords: radiation damage, Frank loops, voids, nickel alloys, scanning/transmission electron microscopy

\section{Introduction}

Ni-based alloys are commonly used in high-temperature applications due to their superior high temperature creep strength and were considered for nuclear reactor systems during fast reactor development programs in the '70s and '80s [1-6]. High$\mathrm{Cr}$ Ni-based alloys are currently used primarily in systems in which there is no neutron flux, such as steam generators, as they have been found to be susceptible to irradiation-induced embrittlement [6]. However, there is a renewed interest in radiation damage effects in Ni-based alloys due to their excellent corrosion resistance, especially in molten salt reactor environments [7, 8]. In these environments Cr-content, usually added to increase oxidation resistance, is considered detrimental as it is preferentially leeched by the fluoride salts [9]. As such, an understanding of radiation damage effects in low-Cr Ni-based alloys is desired.

Many prior radiation effects studies on Ni-based alloys focused on the Nimonic PE16 Ni-Fe-Cr alloy [1-5] and there is considerable literature on composition effects in austenitic stainless steels and ternary model alloy systems [3, 10-13]. However, only a few fundamental studies have been performed to study $\mathrm{Cr}$ content effects on the radiation response of Ni-based alloys. Hudson and Ashby showed that increases in $\mathrm{Cr}$ content tended to reduce swelling in $\mathrm{Ni}$-irradiated $\mathrm{Ni}-\mathrm{Cr}$ binary systems and swelling rates for $\mathrm{Ni}-\mathrm{Cr}$ continued to increase for higher damage doses, rather than saturate as for pure Ni [14]. Garner

${ }^{*}$ Corresponding author: Samuel A. Briggs (凶: sabriggs2@wisc.edu) has postulated that atomic ordering effects may influence void swelling [15], and Robinson and Jenkins have demonstrated weak dependence of dislocation loop formation on $\mathrm{Cr}$ content [16]. Finally, Barr et al. investigated the effects of grain boundary character on the radiation-induced segregation response in a Ni-5Cr alloy [17]. Extrapolation of data from these analogous systems can help to develop Ni-based alloys for the next generation reactor applications. However, more work is required to understand the fundamentals of the radiation response of these alloys.

Ion irradiation experiments have long been used to simulate neutron radiation damage in reactor environments; comparable damage levels are achieved much more rapidly and the resulting samples are typically non-radioactive, making the logistics of sample handling post-irradiation much easier. In this study both protons and $\mathrm{Ni}$ ions have been used to induce damage with the purpose of comparing the effect of dose rate on the induced microstructure, though other factors such as the efficiency of producing mobile point defects and gradients in induced damage must be considered in the context of the presented results. While no neutron irradiation experiments have been performed in the current work, the insights gained can be extrapolated to predict in-core radiation response, though the best way to reconcile the differences in the resulting microstructures induced by neutrons and different types of ions is a topic of debate and has been the focus of several studies [18-23].

The present study investigates the effects of $\mathrm{Cr}$ content, irradiation temperature, and irradiating species on the resulting microstructure of ion irradiated $\mathrm{Ni}$-based alloys with a focus 
on the formation of dislocation loops and voids. The dislocation loop structures seen in this system are faulted Frank loops commonly seen in other irradiated austenitic steels [24, 25] and are the primary contributors to radiation-induced hardening and embrittlement effects. Voids are responsible for radiationinduced void swelling, and both are typically considered to be detrimental to materials performance.

\section{Experimental details}

Two binary model Ni-Cr alloys of nominal composition 5 wt.\% $\mathrm{Cr}$ and $18 \mathrm{wt} . \% \mathrm{Cr}$ (referred to henceforth as $\mathrm{Ni}-5 \mathrm{Cr}$ and $\mathrm{Ni}-18 \mathrm{Cr}$, respectively) were vacuum arc melted and cast in a water-cooled copper hearth and recrystallized by cold-rolling to $50 \%$ of their original thickness followed by annealing for one hour at $1050{ }^{\circ} \mathrm{C}$. These two compositions were selected because they represent binary analogs to a broader family of Ni-based alloys that contain $\mathrm{Cr}$ primarily for high-temperature oxidation resistance and creep strength. Their relatively pure compositions allow us to eliminate the effects of minor alloying elements from this study. The composition of these materials was verified using inductively coupled plasma optical emission spectroscopy (ICP-OES). The results of this analysis are shown in Table 1. Observed impurities are dilute enough such that differences in their concentration between the two materials are not expected to significantly affect radiation response behavior.

Table 1: Summary of bulk alloy compositions for $\mathrm{Ni}-5 \mathrm{Cr}$ and $\mathrm{Ni}-18 \mathrm{Cr}$ in weight percent

\begin{tabular}{c|cccccccc} 
Alloy & $\mathbf{C r}$ & $\mathbf{N i}$ & $\mathbf{C}$ & $\mathbf{S i}$ & $\mathbf{C o}$ & $\mathbf{P}$ & $\mathbf{S}$ & Other Minors \\
\hline \hline Ni-5Cr & 5.00 & 94.94 & 0.007 & 0.01 & 0.01 & $<0.005$ & 0.005 & $<0.01$ \\
Ni-18Cr & 17.90 & 82.02 & 0.016 & 0.01 & 0.01 & $<0.005$ & 0.006 & $<0.01$
\end{tabular}

After recrystallization, the samples were examined using electron backscatter diffraction (EBSD). Defect-free sample surfaces were prepared by mechanical polishing with $\mathrm{SiC}$ paper to 800 grit before electropolishing with an electrolyte solution of $30 \%$ nitric acid, $10 \%$ sulfuric acid, $10 \%$ orthophosphoric acid and 50\% glacial acetic acid [26].

Proton irradiations were conducted at the University of Wisconsin Ion Beam Lab (UW-IBL) on a 3.4 MV Pelletron tandem accelerator with $2 \mathrm{MeV}$ ions for approximately 100 hours until a final fluence of $2.58 \times 10^{19}$ ions $/ \mathrm{cm}^{2}$ was achieved at a nominal flux of $6.77 \times 10^{13}$ ions $/ \mathrm{cm}^{2} \mathrm{~s}$. Target temperatures of 400 and $500 \pm 15^{\circ} \mathrm{C}$ were monitored using two thermocouples mounted on either end of the sample stage and was controlled primarily by optimizing beam current through minimal adjustments. Ni ion irradiations were performed at the Sandia National Laboratories Ion Beam Laboratory on the $6 \mathrm{MV}$ tandem Van de Graaff accelerator using $20 \mathrm{MeV}$ ions for approximately 4 hours until a final fluence of $1.9 \times 10^{16}$ ions $/ \mathrm{cm}^{2}$ was achieved at a nominal flux of $1.32 \times 10^{12}$ ions $/ \mathrm{cm}^{2} \mathrm{~s}$. Temperature was controlled using a button heater coupled with LabVIEW software and was monitored using spot-welded thermocouples and maintained at $500 \pm 10{ }^{\circ} \mathrm{C}$.

Damage profiles for both the proton and $\mathrm{Ni}$ ion irradiations were computed using the SRIM-2008 code [27]. The parame- (a)

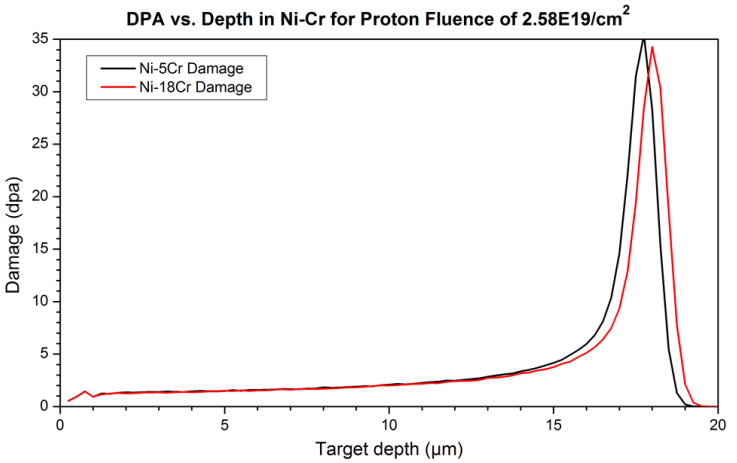

(b)

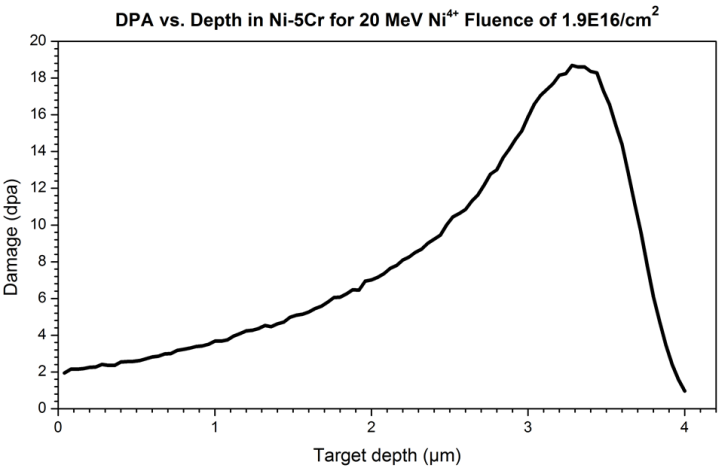

Figure 1: (a) Damage profile for $2 \mathrm{MeV}$ proton irradiations in both $\mathrm{Ni}-\mathrm{Cr}$ alloys. Damage profiles are extremely similar and are assumed to be equivalent for the purpose of this experiment (studied region from 0 to $10 \mu \mathrm{m}$ ). (b) Damage profile for $20 \mathrm{MeV} \mathrm{Ni}^{4+}$ irradiations in Ni-5Cr. Microstructural investigation took place at a target depth of $1 \mu \mathrm{m}$, corresponding to a nominal damage dose of 3.4 dpa. Damage profiles generated using the SRIM-2008 software [27].

ters were selected to comply with the methodology established by Stoller et al. [28]. The resulting damage profiles for the proton and Ni-ion irradiations are shown in Figure 1. A nominal dose of approximately 1.6 displacements per atom (dpa) was achieved in the region examined for the proton-irradiated materials, which extended to a maximum depth of $10 \mu \mathrm{m}$, at an average damage rate of $4.2 \times 10^{-6} \mathrm{dpa} / \mathrm{s}$. The dose achieved in the Ni-irradiated specimens varied more significantly with depth prior to the end of range damage — as such, analysis was performed at a depth of $1 \mu \mathrm{m}$ corresponding to a nominal dose of $3.4 \mathrm{dpa}$. The higher dose in the Ni-ion irradiation experiment was required to saturate radiation-induced segregation in this material, the results of which has been reported previously [17].

Transmission electron microscopy (TEM) techniques were employed to investigate the irradiated microstructures. Samples for TEM analysis were prepared from the unirradiated specimens using electrolytic jet thinning utilizing the same electrolyte solution used for EBSD sample preparation. TEM specimens from irradiated materials were prepared using the focused ion beam (FIB) lift-out method on the FEI Quanta 3D FEG at the Microscopy and Characterization Suite located at the Center for Advanced Energy Studies (CAES) in Idaho. The specimens were prepared from random locations on the irradiated surface and sampled multiple grains. Lift-outs were mounted on cop- 
per Omniprobe FIB grids and cleaned with a $5 \mathrm{kV}$ (Ga) FIB beam to minimize FIB-induced radiation damage. Frank loops residing on the four $\{111\}$ planes of the face centered cubic (fcc) lattice with Burgers vector $a / 3\{111\}$ were imaged using a relrod dark field imaging technique with a $200 \mathrm{kV}$ accelerating voltage on the FEI Tecnai TF-30 TEM/STEM and the JEOL JEM2100 TEM/STEM at the University of Wisconsin-Madison and Drexel University, respectively. The imaging conditions were set in selected area diffraction mode by tilting from the [011] zone axis until a two beam condition was met with the $\mathbf{g}=$ $31 \overline{1}$ reflection and then centering the smallest objective aperture

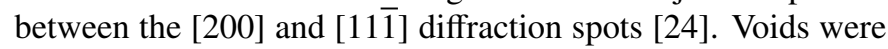
imaged using scanning transmission electron microscopy highangle annular dark field (STEM-HAADF) imaging with $200 \mathrm{kV}$ electrons on the FEI Titan Aberration-corrected (S)TEM at the University of Wisconsin-Madison. Areal defect densities were obtained through manual counting in the ImageJ software [29]. At least three separate micrographs from different sample regions were used for statistical analysis. Sample thicknesses for number density determination were calculated using the electron energy loss spectroscopy (EELS) log-ratio method with an assumed electron mean free path for pure $\mathrm{Ni}$ of $98 \mathrm{~nm}$ for 200 $\mathrm{keV}$ electrons [30]. EELS thickness measurements were taken at five different regions for each sample and averaged to determine the mean specimen thickness.

A cluster dynamics (CD) model was used for simulating loop evolution under proton irradiation to understand mechanisms for loop evolution behavior in $\mathrm{Ni}-5 \mathrm{Cr}$ and $\mathrm{Ni}-18 \mathrm{Cr}$. The $\mathrm{CD}$ simulation technique predicts microstructure evolution in a system described as a gas of non-interacting clusters. The clusters are defined by a single parameter, their size or the number of atoms they contain. The evolution of clusters is deduced from reaction rate theory equations. A previously established CD model for defect evolution based on Duparc et al. and Pokor et al. [31, 32] was used in this study. In this model only single interstitials and single vacancies are considered mobile. Incascade clustering of defects $[33,34]$ under proton irradiation based on Gan et al. is also included in the model [35]. The material parameters, cascade production properties, and environmental parameters (dose rate and temperature) for the $\mathrm{CD}$ model are listed in Table 2. In most cases the properties of pure $\mathrm{Ni}$ were considered due to lack of data for specific $\mathrm{Ni}-5 \mathrm{Cr}$ and Ni-18Cr alloys. The binding energy of dimer interstitials is used as fitting parameter, as discussed below.

\section{Results and discussion}

\subsection{Unirradiated microstructure}

Inverse pole figure maps for each material obtained via EBSD are shown in Figure 2. It can be seen that the grains are equiaxed, with an area averaged grain size (including twin boundaries) of 163.9 and 106.6 microns for the $\mathrm{Ni}-5 \mathrm{Cr}$ and $\mathrm{Ni}$ $18 \mathrm{Cr}$ specimens, respectively. Due to these large grain sizes compared to implantation and analysis depths in these materials the presented results are expected to be representative of bulk material behavior.

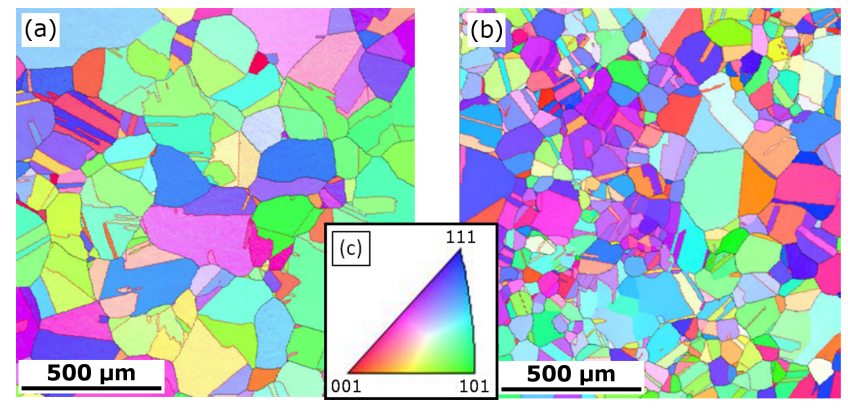

Figure 2: Representative inverse pole figure (IPF) of (a)Ni-5Cr and (b) $\mathrm{Ni}-18 \mathrm{Cr}$ sample materials prior to irradiation. IPF key is shown in (c).

TEM investigation on the unirradiated jet-polished specimens showed a clean microstructure with very few dislocation structures and a complete absence of voids. In addition, TEM examination of the $\mathrm{Ni}$-irradiated foils in regions beyond the damage range showed minimal FIB damage artifacts. Based on these observations it is concluded that all obvious microstructural defects are a result of the ion irradiation treatment.

\subsection{Frank loops in irradiated $\mathrm{Ni}-\mathrm{Cr}$}

Frank loops in irradiated Ni-Cr specimens showed distinct differences in density and size for different compositions and irradiation conditions. Representative TEM relrod micrographs showing these loop structures for the five investigated conditions are shown in Figure 3 and plots illustrating the loop sizes and densities are shown in Figure 4. As is evident from Figure 5, irradiations at $400{ }^{\circ} \mathrm{C}$ tended to result in a higher density of Frank loops as compared to irradiations at $500{ }^{\circ} \mathrm{C}$ and the higher irradiation temperature induced a slight increase in the loop size. Simulation of annealing effects in 304L stainless steels by Busby et al. have illustrated that loop stability can be greatly affected by the temperature increase from 400 to $500{ }^{\circ} \mathrm{C}$, especially over the course of a $100 \mathrm{hr}$ irradiation [40]. These observations imply that an increase in point defect recombination and annihilation due to enhanced mobility at $500{ }^{\circ} \mathrm{C}$ combined with increased thermal emission ultimately results in a reduced number of dislocation loops. Furthermore, the loops that do nucleate tend to absorb more point defects and increase in size. In addition, the lower density of Frank loops at $500{ }^{\circ} \mathrm{C}$ could be attributed to the unfaulting of Frank loops to network, perfect $1 / 2\langle 111\rangle$ dislocations. Zhang et al. recently indicated unfaulting of interstitial Frank loops at $500{ }^{\circ} \mathrm{C}$ during $1 \mathrm{MeV} \mathrm{Kr}^{2+}$ irradiations of Inconel $\mathrm{X}-750$ while also indicating a lower density of total loops observed at $500{ }^{\circ} \mathrm{C}$ than at $400{ }^{\circ} \mathrm{C}$ [41]. The growth and subsequent unfaulting of Frank loops at higher temperatures is consistent with the slightly larger loop size and small Frank loop density observed between 400 and $500{ }^{\circ} \mathrm{C}$ examined in the proton irradiations. These temperature trends are consistent with observed loop morphologies in $\mathrm{Ni}$ ion and neutron irradiated 316L stainless steel systems [42-44].

Additionally, it was observed that the self-ion irradiated Ni$5 \mathrm{Cr}$ showed a higher density of larger loops than the protonirradiated $\mathrm{Ni}-5 \mathrm{Cr}$ at $500{ }^{\circ} \mathrm{C}$. Due to the differences in dose it is 
Table 2: Parameters used for $\mathrm{Ni}-5 \mathrm{Cr}$ and $\mathrm{Ni}-18 \mathrm{Cr}$ cluster dynamics model.

\begin{tabular}{|c|c|c|}
\hline Parameter & Value & Reference \\
\hline Lattice parameter & $3.524 \AA$ & \\
\hline Temperature & $400{ }^{\circ} \mathrm{C}$ & \\
\hline Interstitial migration energy & $0.12 \mathrm{eV}$ & {$[36]$} \\
\hline Vacancy migration energy & $1.02 \mathrm{eV}$ & {$[37]$} \\
\hline Interstitial pre-exponential & $8 \times 10^{-10} \mathrm{~m}^{2} / \mathrm{s}$ & $\begin{array}{l}\text { Calculated assuming } D_{i} \\
\text { is equal to austenitic steels }\end{array}$ \\
\hline Vacancy pre-exponential & $6.7 \times 10^{-7} \mathrm{~m}^{2} / \mathrm{s}$ & {$[37]$} \\
\hline Interstitial formation energy & $4.16 \mathrm{eV}$ & {$[36]$} \\
\hline Vacancy formation energy & $1.79 \mathrm{eV}$ & {$[38]$} \\
\hline Binding energy of interstitial dimer & Fitting parameter & \\
\hline Binding energy of vacancy dimer & $0.05 \mathrm{eV}$ & [39] \\
\hline Recombination radius & $0.7 \mathrm{~nm}$ & {$[32]$} \\
\hline Dislocation density & $1 \times 10^{12} \mathrm{~m}^{-2}$ & \\
\hline Average grain size & $100 \mu \mathrm{m}$ & \\
\hline Burgers vector of the loop assumed to be prismatic & $a / \sqrt{3}$ & \\
\hline Capture efficiency for interstitial by dislocation net & 1.2 & {$[32]$} \\
\hline Capture efficiency for vacancy by dislocation net & 1.0 & {$[32]$} \\
\hline Dose rate & $3.9 \times 10^{-6} \mathrm{dpa} / \mathrm{s}$ & \\
\hline Damage efficiency & 0.90 & {$[35]$} \\
\hline In-cascade interstitial clustering fraction for $2 \mathrm{i}$ & $1 \%$ & {$[35]$} \\
\hline In-cascade interstitial clustering fraction for $3 \mathrm{i}$ & $1 \%$ & {$[35]$} \\
\hline In-cascade interstitial clustering fraction for $4 \mathrm{i}$ & $0.1 \%$ & {$[35]$} \\
\hline In-cascade interstitial clustering fraction for vacancy & $10 \%$ & {$[35]$} \\
\hline Radius of vacancy clusters & $0.5 \mathrm{~nm}$ & {$[35]$} \\
\hline
\end{tabular}

difficult to make one-to-one quantitative comparisons and extricate the effects of using a different irradiating ion species. However, Frank loop morphologies are known to eventually saturate with dose in similar irradiated systems [24, 45], specifically in the 1-1.5 dpa range for ion-irradiated materials [41, 46]. If it is assumed that saturation behavior is similar for the presently considered $\mathrm{Ni}$-irradiated $\mathrm{Ni}-5 \mathrm{Cr}$ alloy, the higher density of observed loops would suggest that the immobile defect clusters generated during the more chaotic damage cascades can aid in loop nucleation. Additionally, the larger loop size distribution may indicate that a larger portion of the produced defects are being absorbed by this high density of nucleated loops instead of annihilating, or that nucleated loops may interact with/absorb these defect clusters to grow at an increased rate.

While an increase in the irradiation temperature increased the loop size for the two compositions studied, changing the $\mathrm{Cr}$ content also had an effect on the loop density. For $400{ }^{\circ} \mathrm{C}$ irradiation, $\mathrm{Ni}-18 \mathrm{Cr}$ showed a higher loop density by approximately a factor of two when compared to Ni-5Cr. This higher density was accompanied with a slight decrease in average loop size. A similar trend is observed as a result of $500{ }^{\circ} \mathrm{C}$ irradiation but with a larger difference in the loop densities between the two compositions. This contradicts observations in a study of room temperature tungsten-irradiated $\mathrm{Ni}-8 \mathrm{Cr}$ and $\mathrm{Ni}-17 \mathrm{Cr}$ by Robin- son et al. in which a lower $\mathrm{Cr}$ content resulted in a higher defect yield (defined as the fraction of displacement cascades which collapse to form point-defect clusters), though the differences in the densities was much less dramatic than observed here and within the reported error bars [16]. It is postulated here that the primary cause for the changes in defect morphologies with different compositions are due to the differences in the energetics of loop nucleation. This was investigated further by using cluster dynamics simulations discussed in the next section. It is noted that the $\mathrm{Ni}-5 \mathrm{Cr}$ specimen irradiated with protons at 500 ${ }^{\circ} \mathrm{C}$ appears to be an outlier in this study, due to the order of magnitude difference in the density of dislocation loops observed as compared to the other specimens. As such, the cluster dynamics simulations focus on the $400{ }^{\circ} \mathrm{C}$ proton-irradiated materials to study the composition effects, as variation of model parameters commensurate with what is expected for such a temperature shift did not yield good fits to this experimental data.

\subsection{Cluster dynamics modeling results}

It is hypothesized that the different loop behavior between $\mathrm{Ni}-5 \mathrm{Cr}$ and $\mathrm{Ni}-18 \mathrm{Cr}$ is due to changes in the initial energetics of the loop, which alters its nucleation. Ab initio calculations have reported strong binding energies between $\mathrm{Cr}$ and interstitials in $\mathrm{Ni}-\mathrm{Cr}$ alloys, with differences between $\mathrm{Ni}-\mathrm{Ni}$ and $\mathrm{Cr}-$ 


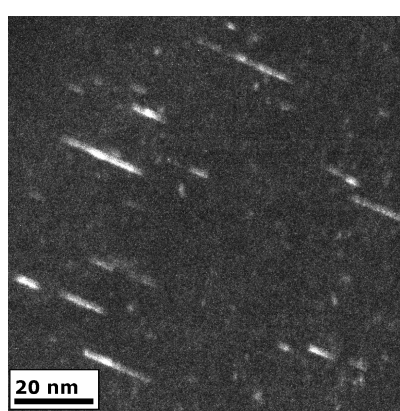

(a) $\mathrm{Ni}-5 \mathrm{Cr}, 400{ }^{\circ} \mathrm{C}, \mathrm{H}^{+}$

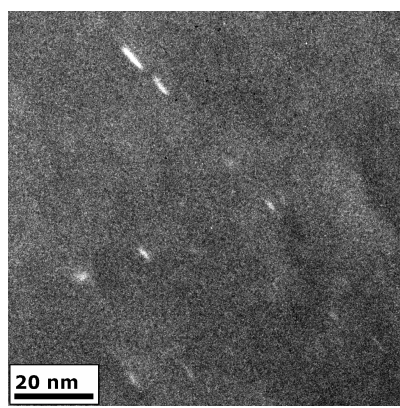

(c) $\mathrm{Ni}-5 \mathrm{Cr}, 500{ }^{\circ} \mathrm{C}, \mathrm{H}^{+}$

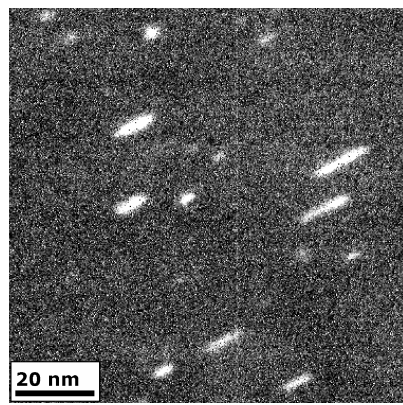

(e) $\mathrm{Ni}-5 \mathrm{Cr}, 500{ }^{\circ} \mathrm{C}, \mathrm{Ni}^{4+}$

Figure 3: Representative TEM relrod micrographs of Frank loop structures in the irradiated $\mathrm{Ni}-\mathrm{Cr}$ materials.

Cr dumbbell stability approaching $1 \mathrm{eV} /$ dumbbell [47]. Therefore, it is expected that increases in $\mathrm{Cr}$ concentration would increase binding energy between dimer interstitials in $\mathrm{Ni}-\mathrm{Cr}$ alloys, likely on the scale of approximately $0.1 \mathrm{eV}$ for a $10 \mathrm{wt} . \%$ change in $\mathrm{Cr}$ content. An increase in interstitial binding will increase loop nucleation, which in turn will increase number density and decrease size. This is exactly what is observed when increasing $\mathrm{Cr}$ content from 5 to $18 \mathrm{wt} . \% \mathrm{Cr}$ at $400{ }^{\circ} \mathrm{C}$.

To further assess if this intuitive understanding is plausible, the aforementioned cluster dynamics (CD) model is used to explore if changes in the dimer interstitial binding energy $\left(E_{b 2 i}\right.$, which is the decrease in energy of an interstitial pair relative to isolated interstitials) on the scale of $0.1 \mathrm{eV}$ can yield the type of changes observed in the experiments. It should be noted that this is a highly approximate model and it is being used only to qualitatively assess if the arguments about $E_{b 2 i}$ are plausible, not provide predictive accuracy. Therefore, $E_{b 2 i}$ is used as a fitting parameter to explore what changes in this quantity

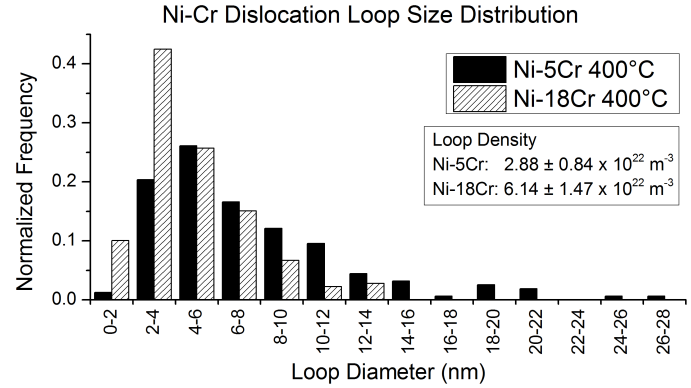

(a) $\mathrm{H}^{+}$-irradiated $\mathrm{Ni}-\mathrm{Cr}$ at $400{ }^{\circ} \mathrm{C}$

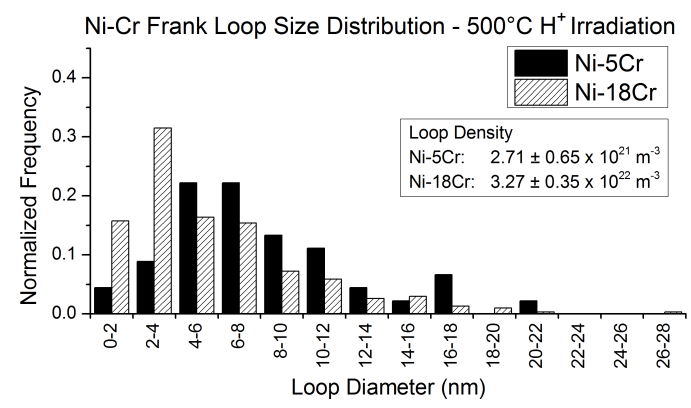

(b) $\mathrm{H}^{+}$-irradiated $\mathrm{Ni}-\mathrm{Cr}$ at $500{ }^{\circ} \mathrm{C}$

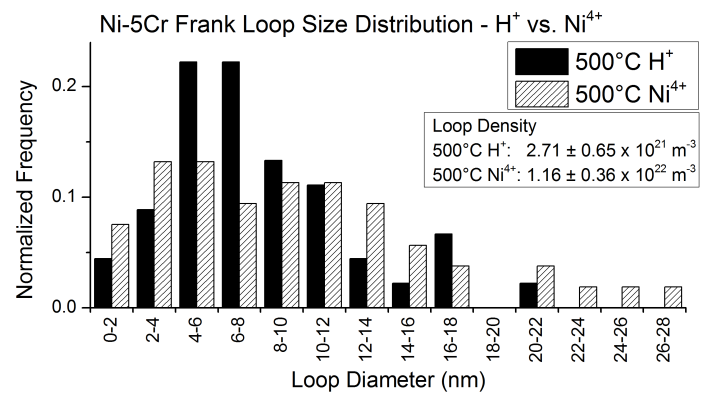

(c) $\mathrm{H}^{+}$- vs. $\mathrm{Ni}^{4+}$-irradiated $\mathrm{Ni}-5 \mathrm{Cr}$ at $500{ }^{\circ} \mathrm{C}$

Figure 4: Comparison of Frank loop densities and size distributions for the different material conditions investigated. Reported error represents one standard deviation for calculated number densities for individual TEM micrographs.

are needed to explain the data. The fitted values are selected to best represent the loop size and number density. For $\mathrm{Ni}-5 \mathrm{Cr}$ the best fit value of $E_{b 2 i}$ is $0.73 \mathrm{eV}$ and for $\mathrm{Ni}-18 \mathrm{Cr}$ the best fit value of $E_{b 2 i}$ is $0.9 \mathrm{eV}$ at $400{ }^{\circ} \mathrm{C}$. Figure 5 shows the results of $\mathrm{CD}$ model compared with experimental data for both $\mathrm{Ni}-5 \mathrm{Cr}$ and $\mathrm{Ni}-18 \mathrm{Cr}$ at $400{ }^{\circ} \mathrm{C}$. The good agreement for both size and number density suggests that the present simple model can provide useful qualitative guidance. The $0.17 \mathrm{eV}$ change in $E_{b 2 i}$ is fully consistent with our hypothesis that changes in the nucleation energetics, or equivalently, in $E_{b 2 i}$, on the scale of approximately $0.1 \mathrm{eV}$ is responsible for the changes in loop properties with $\mathrm{Cr}$ concentration.

\subsection{Voids in irradiated $\mathrm{Ni}-\mathrm{Cr}$}

Voids were imaged using STEM HAADF imaging and differences in the void structures were apparent. Representative images of void structures in the various irradiated $\mathrm{Ni}-\mathrm{Cr}$ conditions are shown in Figure 6 and histograms comparing the void 

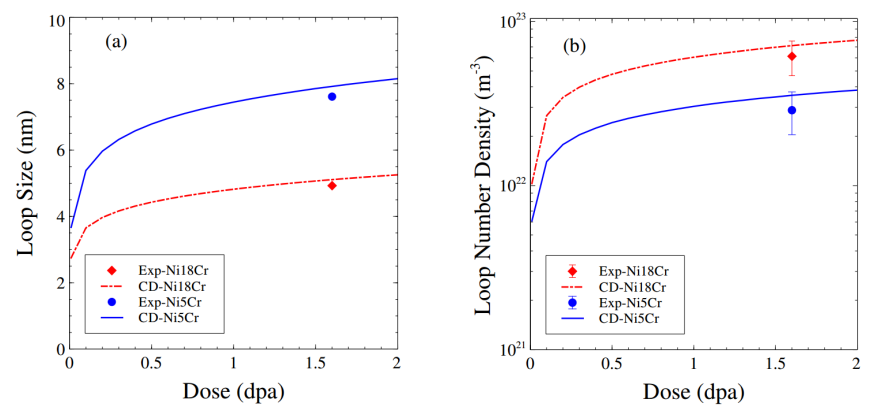

Figure 5: Loop size (a) and number density (b) evolution for $\mathrm{Ni}-5 \mathrm{Cr}$ and $\mathrm{Ni}$ $18 \mathrm{Cr}$ at $400{ }^{\circ} \mathrm{C}$ under proton irradiation. Fitted dimer interstitial binding energy $\left(E_{b 2 i}\right)$ for $\mathrm{Ni}-5 \mathrm{Cr}(0.73 \mathrm{eV})$ and $\mathrm{Ni}-18 \mathrm{Cr}(0.9 \mathrm{eV})$ shows a reasonable coupling between $\mathrm{Cr}$ concentration and $E_{b 2 i}$ (see text for more discussion).

sizes and densities are shown in Figure 7. Void swelling was calculated from the ratio of the volume of the observed voids (assuming spherical geometries) to the total volume analyzed.

Increase in temperature resulted in similar effects for void morphologies as for dislocation loops. Higher temperature irradiations induced a lower density of larger voids. However, this change in morphology with temperature was much more pronounced for voids, with approximately $50 \times$ and $3 \times$ decrease in the observed densities going from $400{ }^{\circ} \mathrm{C}$ to $500{ }^{\circ} \mathrm{C}$ irradiations for $\mathrm{Ni}-5 \mathrm{Cr}$ and $\mathrm{Ni}-18 \mathrm{Cr}$, respectively. Upon high temperature irradiation some voids showed double the diameter of those seen in the lower-temperature irradiated specimens. These results are consistent with observations made in similar systems, and likely originate from increased void nucleation at lower temperatures and from more favorable driving forces for void growth at high temperatures [15, 48].

For the $400{ }^{\circ} \mathrm{C}$ irradiation, the void size distributions are similar and the error associated with the calculated densities overlap for the $\mathrm{Ni}-5 \mathrm{Cr}$ and $\mathrm{Ni}-18 \mathrm{Cr}$, whereas the $500{ }^{\circ} \mathrm{C}$ irradiated materials show dramatically different size distributions and an order of magnitude difference in the void densities. The $400{ }^{\circ} \mathrm{C}$ proton-irradiated materials are likely more indicative of composition dependence, in which case $\mathrm{Cr}$ additions suppresses swelling, likely by changing void nucleation behavior. This conclusion is consistent with results from earlier studies on void swelling binary and ternary Ni-based alloys in which initial swelling is suppressed by $\mathrm{Cr}$ additions but steady-state swelling rates are more or less unaffected $[12,14,15]$.

The differences in void microstructure resulting from $\mathrm{Ni}$ ion irradiation is also dramatic with a higher density of much smaller voids observed when compared to proton-irradiated materials. This result is consistent with the hypothesis that lower dose rates incur more swelling and larger voids for the same dose, which has been well supported in austenitic steel systems [49]. In this case there is likely a large effect just due to time held at temperature - the Ni-ion irradiations took approximately 4 hours whereas the proton irradiation took a little over 100 hours, giving much more time for point defect diffusion and void agglomeration. The higher density of voids generated in the shorter Ni-irradiation may be indicative that higher disorder caused by in-cascade clustering effects aid in the void

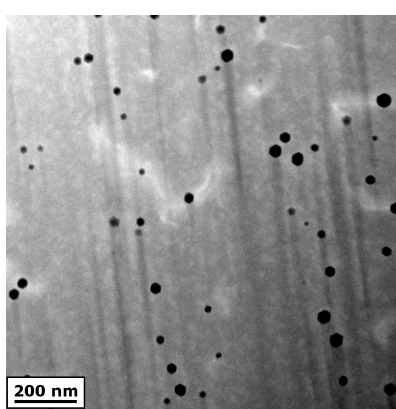

(a) $\mathrm{Ni}-5 \mathrm{Cr}, 400{ }^{\circ} \mathrm{C}, \mathrm{H}^{+}$

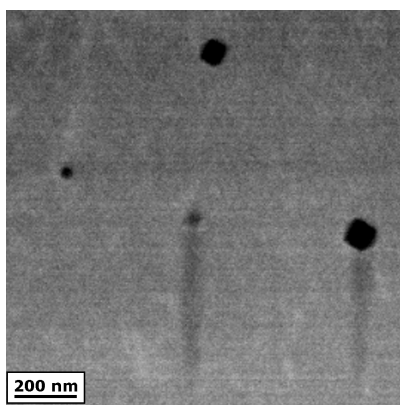

(c) $\mathrm{Ni}-5 \mathrm{Cr}, 500{ }^{\circ} \mathrm{C}, \mathrm{H}^{+}$

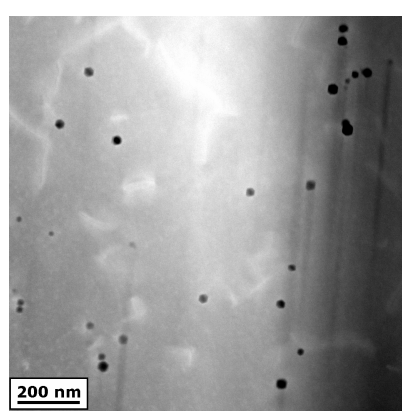

(b) $\mathrm{Ni}-18 \mathrm{Cr}, 400{ }^{\circ} \mathrm{C}, \mathrm{H}^{+}$

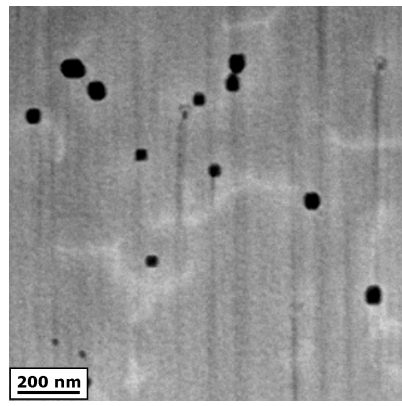

(d) $\mathrm{Ni}-18 \mathrm{Cr}, 500^{\circ} \mathrm{C}, \mathrm{H}^{+}$

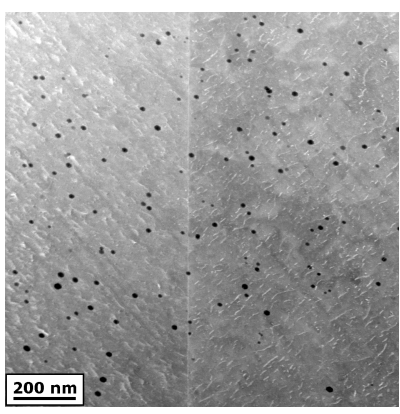

(e) $\mathrm{Ni}-5 \mathrm{Cr}, 500{ }^{\circ} \mathrm{C}, \mathrm{Ni}^{4+}$

Figure 6: Representative STEM HAADF images showing void structures in the irradiated Ni-Cr alloys.

nucleation process.

\section{Conclusions}

In this study, the irradiation microstructures of $\mathrm{Ni}-5 \mathrm{Cr}$ and $\mathrm{Ni}-18 \mathrm{Cr}$ model alloys were investigated using analytical transmission electron microscopy techniques. A summary of this analysis is provided in Table 3. Most notably, our results indicate that the irradiation temperature has a distinct effect on the damage morphology. By increasing the proton irradiation temperature from $400{ }^{\circ} \mathrm{C}$ to $500{ }^{\circ} \mathrm{C}$, an increase in size and a decrease in density was observed for dislocation loop and voids. This effect is proposed to originate from increased thermal motion of point defects, which results in more defects finding and combining with existing clusters than nucleating new clusters. Cluster dynamic simulations were in good agreement with the most robust experimental observations, and suggested that $\mathrm{Cr}$ 
Table 3: Summary of the observed Frank loop and void morphologies for all conditions studied.

\begin{tabular}{|c|c|c|c|c|c|c|c|c|c|}
\hline Condition & $\begin{array}{c}\text { Number of } \\
\text { Loops Identified }\end{array}$ & $\begin{array}{l}\text { Volume Analyzed } \\
\qquad\left(\mathrm{nm}^{3}\right)\end{array}$ & $\begin{array}{l}\text { Loop Number } \\
\text { Density }\left(\mathrm{m}^{-3}\right)\end{array}$ & $\begin{array}{l}\text { Average Loop } \\
\text { Diameter (nm) }\end{array}$ & $\begin{array}{c}\text { Number of } \\
\text { Voids Identified }\end{array}$ & $\begin{array}{l}\text { Volume Analyzed } \\
\qquad\left(\mathrm{nm}^{\wedge} 3\right)\end{array}$ & $\begin{array}{l}\text { Void Number } \\
\text { Density }\left(\mathrm{m}^{-3}\right)\end{array}$ & $\begin{array}{c}\text { Average Void } \\
\text { Diameter }(\mathrm{nm})\end{array}$ & $\begin{array}{c}\text { Estimated } \\
\text { Swelling }\end{array}$ \\
\hline $\mathrm{Ni}-5 \mathrm{Cr}, 400^{\circ} \mathrm{C}, \mathrm{H}^{+}, 1.6 \mathrm{dpa}$ & 157 & $2.15 \times 10^{7}$ & $2.88 \pm 0.84 \times 10^{22}$ & 7.6 & 176 & $7.68 \times 10^{8}$ & $2.28 \pm 0.71 \times 10^{20}$ & 26.4 & $0.30 \%$ \\
\hline $\mathrm{Ni}-5 \mathrm{Cr}, 500^{\circ} \mathrm{C}, \mathrm{H}^{+}, 1.6 \mathrm{dpa}$ & 46 & $8.28 \times 10^{7}$ & $2.71 \pm 0.65 \times 10^{21}$ & 8.7 & 41 & $1.32 \times 10^{10}$ & $4.31 \pm 2.23 \times 10^{18}$ & 58.7 & $0.10 \%$ \\
\hline $\mathrm{Ni}-18 \mathrm{Cr}, 400^{\circ} \mathrm{C}, \mathrm{H}^{+}, 1.6 \mathrm{dpa}$ & 188 & $1.23 \times 10^{7}$ & $6.14 \pm 1.47 \times 10^{22}$ & 4.7 & 204 & $1.50 \times 10^{9}$ & $1.37 \pm 0.57 \times 10^{20}$ & 24.2 & $0.05 \%$ \\
\hline $\mathrm{Ni}-18 \mathrm{Cr}, 500^{\circ} \mathrm{C}, \mathrm{H}^{+}, 1.6 \mathrm{dpa}$ & 305 & $3.72 \times 10^{7}$ & $3.27 \pm 0.35 \times 10^{22}$ & 5.6 & 421 & $1.28 \times 10^{10}$ & $3.34 \pm 1.00 \times 10^{19}$ & 37.7 & $0.14 \%$ \\
\hline $\mathrm{Ni}-5 \mathrm{Cr}, 500{ }^{\circ} \mathrm{C}, \mathrm{Ni}^{4+}, 3.4 \mathrm{dpa}$ & 53 & $1.84 \times 10^{7}$ & $1.16 \pm 0.36 \times 10^{22}$ & 10.1 & 222 & $2.15 \times 10^{8}$ & $9.93 \pm 1.17 \times 10^{20}$ & 11.2 & $0.07 \%$ \\
\hline
\end{tabular}

content might be enhancing dislocation loop nucleation behavior through increasing the stability of the smallest clusters. Assigning interstitial binding energies of $0.73 \mathrm{eV}$ to $0.9 \mathrm{eV}$ for 5 wt.\% $\mathrm{Cr}$ and 18 wt.\% $\mathrm{Cr}$ alloys, respectively, resulted in a good fit to the experimental data.

$\mathrm{Ni}$-irradiated $\mathrm{Ni}-\mathrm{Cr}$ specimens showed higher densities of much smaller voids than the proton-irradiated samples, which is likely a consequence of the much higher dose rate coupled with less time at temperature for defect structures to organize over the shorter course of the Ni irradiation (4h) as compared to proton irradiation $(100 \mathrm{~h})$. However, the higher density of voids upon Ni-irradiation may be indicative of in-cascade clustering effects aiding in void nucleation. While comparing the effects of proton and heavy ion irradiations is valuable, further study on neutron irradiated $\mathrm{Ni}-\mathrm{Cr}$ alloys is required, as the ultimate goal of ion irradiations is to emulate neutron damage in the best possible way. Additionally, the alloys that will be employed in nuclear components such as, for example, in molten salt reactor systems will likely not be binary systems. However, this fundamental study of radiation tolerance in binary $\mathrm{Ni}-\mathrm{Cr}$ alloys gives insight into the mechanisms of defect formation and serves as a basis for comparison for these future studies.

\section{Acknowledgements}

Research was sponsored by the US National Science Foundation, Grant No. 1105640. Proton irradiation of Ni-Cr alloys was performed at the UW Ion Beam Laboratory. Ni ion irradiation of Ni-Cr alloys was fully supported by the Division of Materials Science and Engineering, Office of Basic Energy Sciences, U.S. Department of Energy. Sandia National Laboratories is a multi-program laboratory managed and operated by Sandia Corporation, a wholly owned subsidiary of Lockheed Martin Corporation, for the U.S. Department of Energy's National Nuclear Security Administration under contract DEAC04-94AL85000. Focused ion beam sample preparation was performed at the MaCS Laboratory at the Center for Advanced Energy Studies at Idaho National Laboratory. Scanning and transmission electron microscopy was performed at the University of Wisconsin-Madison Materials Science Center. Funding for SAB was provided by the DOE Office of Nuclear Energy's Nuclear Energy University Programs.

\section{References}

[1] J.F. Bates and R.W. Powell. Irradiation-induced swelling in commercial alloys. Journal of Nuclear Materials, 2:200-213, 1980.
[2] K. Farrell and N.H. Packan. Damage structure in Nimonic PE16 alloy ion bombarded to high doses and gas levels. Journal of Nuclear Materials, 103-104:1059-1062, 1981.

[3] L.E. Thomas and D.S. Gelles. Swelling in commercial Fe-Cr-Ni based alloys under electron irradiation. Journal of Nuclear Materials, 109:490503, 1982.

[4] W.J.S. Yang. Grain boundary segregation in solution-treated Nimonic PE16 during neutron irradiation. Journal of Nuclear Materials, 108109:339-346, 1982.

[5] R.M. Boothby. The microstructure of fast neutron irradiated nimonic PE16. Journal of Nuclear Materials, 230(2):148-157, 1996.

[6] R.M. Boothby. 4.04 - Radiation Effects in Nickel-Based Alloys. In Rudy J.M. Konings, editor, Comprehensive Nuclear Materials, pages 123-150. Elsevier Inc., 2012.

[7] Y. Guérin, G.S. Was, and S.J. Zinkle. Materials Challenges for Advanced Nuclear Energy Systems. MRS Bulletin, 34(January):13, 2009.

[8] T. Yonezawa. 2.08 - Nickel Alloys: Properties and Characteristics. In Rudy J.M. Konings, editor, Comprehensive Nuclear Materials, pages 233-266. Elsevier Inc., 2012.

[9] W.D. Manly, J.W. Allen, W.H. Cook, J.H. DeVan, D.A. Douglas, H. Inouye, D.H. Jansen, P. Patriarca, T.K. Roche, G.M. Slaughter, A. Taboada, and G.M. Tolson. Construction Materials for Molten-Salt Reactors. In J.A. Lane, editor, Fluid-Fueled Reactors, chapter 13. Addison-Wesley, NY, 1958.

[10] F.A. Garner and W.G. Wolfer. Factors which determine the swelling behavior of austenitic stainless steels. Journal of Nuclear Materials, 123:201-206, 1984.

[11] H.R. Brager, F.A. Garner, and M.L. Hamilton. The influence of composition on microstructural evolution and mechanical properties of irradiated Fe-Ni-Cr ternaries. Journal of Nuclear Materials, 133-134:594-598, 1985.

[12] T. Muroga, F.A. Garner, and S. Ohnuki. Microstructural investigation of swelling dependence on nickel content in fast neutron-irradiated $\mathrm{Fe}-\mathrm{Cr}$ $\mathrm{Ni}$ austenitic ternaries. Journal of Nuclear Materials, 179-181:546-549, 1991.

[13] F.A. Garner, C.A. Black, and D.J. Edwards. Factors which control the swelling of Fe-Cr-Ni ternary austenitic alloys. Journal of Nuclear Materials, 245:124-130, 1997.

[14] J.A. Hudson and S.J. Ashby. Void formation in a binary nickel alloy. Technical report, Atomic Energy Research Establishment, 1974.

[15] F.A. Garner. The possible influence of order-disorder transformations on the swelling of $85 \mathrm{Ni}-15 \mathrm{Cr}$ nichrome alloy. Journal of Nuclear Materials, 148(3):288-293, 1987.

[16] T. M. Robinson and M. L. Jenkins. Heavy-ion irradiation of nickel and nickel alloys. Philosophical Magazine A, 43(4):999-1015, 1981.

[17] C.M. Barr, L. Barnard, J.E. Nathaniel, K. Hattar, K.A. Unocic, I. Szlurfarska, D.D. Morgan, and M.L. Taheri. Grain boundary character dependence of radiation-induced segregation in a model Ni-Cr alloy. Journal of Materials Research, 30(09):1290-1299, 2015.

[18] G.S. Was and T.R. Allen. Intercomparison of microchemical evolution under various types of particle irradiation. Journal of Nuclear Materials, 205(Oct 1993):332-338, 1993.

[19] G.S. Was, J.T. Busby, T.R. Allen, E.A. Kenik, A. Jenssen, S.M. Bruemmer, J. Gan, A.D. Edwards, P.M. Scott, and P.L. Andresen. Emulation of neutron irradiation effects with protons: validation of principle. Journal of Nuclear Materials, 300:198-216, 2002.

[20] T.R. Allen, J.I. Cole, J. Gan, G.S. Was, R. Dropek, and E.A. Kenik. Swelling and radiation-induced segregation in austentic alloys. Journal of Nuclear Materials, 342(1-3):90-100, jun 2005.

[21] G.S. Was and R.S. Averback. 1.07 - Radiation Damage Using Ion Beams. 


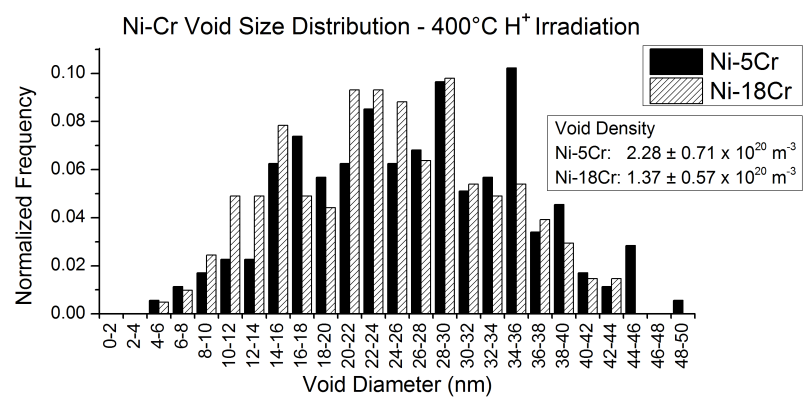

(a) $\mathrm{H}^{+}$-irradiated $\mathrm{Ni}-\mathrm{Cr}$ at $400{ }^{\circ} \mathrm{C}$

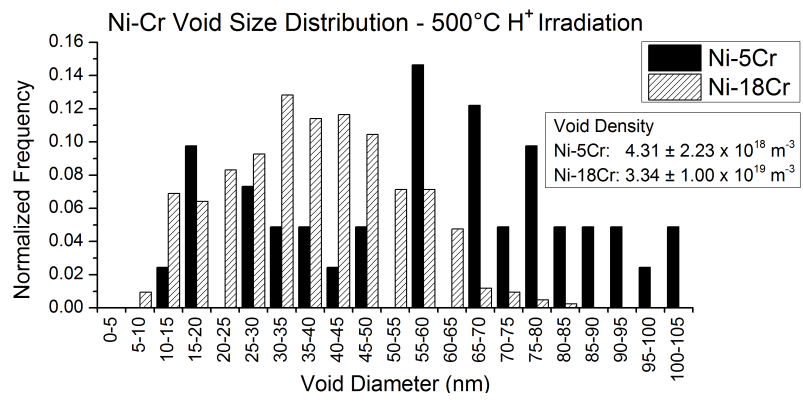

(b) $\mathrm{H}^{+}$-irradiated $\mathrm{Ni}-\mathrm{Cr}$ at $500{ }^{\circ} \mathrm{C}$

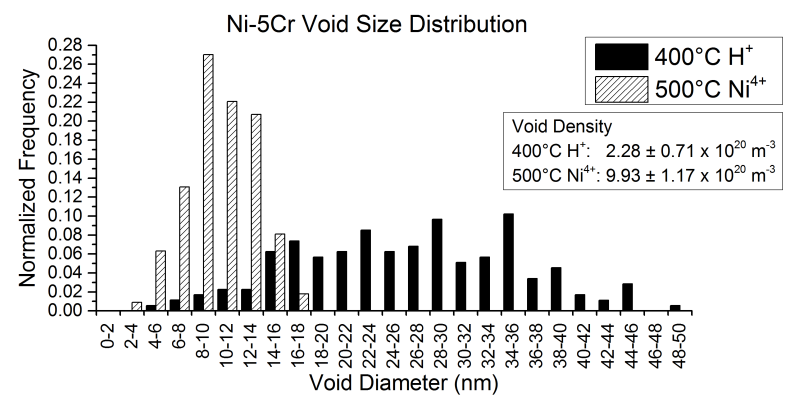

(c) $\mathrm{H}^{+}$- vs. $\mathrm{Ni}^{4+}$-irradiated $\mathrm{Ni}-5 \mathrm{Cr}$ at 400 and $500{ }^{\circ} \mathrm{C}$, respectively.

Figure 7: Comparison of void densities and size distributions for the different material conditions investigated. Reported error represents one standard deviation for calculated number densities for individual STEM micrographs.

In Rudy J.M. Konings, editor, Comprehensive Nuclear Materials, pages 195-221. Elsevier Inc., 2012.

[22] M.J. Swenson and J.P. Wharry. The comparison of microstructure and nanocluster evolution in proton and neutron irradiated $\mathrm{Fe}-9 \% \mathrm{Cr}$ ODS steel to 3 dpa at $500{ }^{\circ}$ C. Journal of Nuclear Materials, 467:97-112, 2015.

[23] S. Ishino, N. Sekimura, K. Murakami, and H. Abe. Some remarks on insitu studies using TEM-heavy-ion accelerator link from the stand point of extracting radiation damage caused by fast neutrons. Journal of Nuclear Materials, pages 1-8, 2015.

[24] D.J. Edwards, E.P. Simonen, and S.M. Bruemmer. Evolution of fine-scale defects in stainless steels neutron-irradiated at $275{ }^{\circ} \mathrm{C}$. Journal of Nuclear Materials, 317(1):13-31, apr 2003.

[25] J. Gan, E.P. Simonen, S.M. Bruemmer, L. Fournier, B.H. Sencer, and G.S. Was. The effect of oversized solute additions on the microstructure of $316 \mathrm{SS}$ irradiated with $5 \mathrm{MeV} \mathrm{Ni++} \mathrm{ions} \mathrm{or} 3.2 \mathrm{MeV}$ protons. Journal of Nuclear Materials, 325(2-3):94-106, feb 2004.

[26] T.R. Allen. Modeling of radiation-induced segregation in austenitic FeCr-Ni alloys. PhD thesis, University of Michigan, 1997.

[27] J.F. Ziegler, J.P. Biersack, and M.D. Ziegler. SRIM - The Stopping and Range of Ions in Matter. Ion Implantation Press, 2008.

[28] R.E. Stoller, M.B. Toloczko, G.S. Was, A.G. Certain, S. Dwaraknath, and F.A. Garner. On the use of SRIM for computing radiation damage expo- sure. Nuclear Instruments and Methods in Physics Research Section B: Beam Interactions with Materials and Atoms, 310:75-80, 2013.

[29] C.A. Schneider, W.S. Rasband, and K.W. Eliceiri. NIH Image to ImageJ: 25 years of image analysis. Nature Methods, 9(7):671-675, 2012.

[30] R.F. Egerton. Electron Energy-Loss Spectroscopy in the Electron Microscope. Springer, third edition, 2011.

[31] A.H. Duparc, C. Moingeon, N. Smetniansky-De-Grande, and A. Barbu. Microstructure modelling of ferritic alloys under high flux $1 \mathrm{MeV}$ electron irradiations. Journal of Nuclear Materials, 302(2-3):143-155, 2002.

[32] C. Pokor, Y. Brechet, P. Dubuisson, J. P. Massoud, and a. Barbu. Irradiation damage in 304 and 316 stainless steels: Experimental investigation and modeling. Part I: Evolution of the microstructure. Journal of Nuclear Materials, 326(1):19-29, 2004.

[33] John A. Brinkman. On the nature of radiation damage in metals. Journal of Applied Physics, 25(8):961-970, 1954.

[34] G.S. Was. Fundamentals of Radiation Materials Science. Springer, 2007.

[35] J. Gan, G.S. Was, and R.E. Stoller. Modeling of microstructure evolution in austenitic stainless steels irradiated under light water reactor condition. Journal of Nuclear Materials, 299:53-67, 2001.

[36] N.Q. Lam and L. Dagens. Calculations of the properties of single and multiple defects in nickel. Journal of Physics F: Metal Physics, 16(10):1373, 1986.

[37] L. Zhao, R. Najafabadi, and D. J. Srolovitz. Determination of vacancy and atomic diffusivities in solid solution alloys. Acta Materialia, 44(7):27372749,1996

[38] P. Ehrhart, P. Jung, H. Schultz, and H. Ullmaier. Atomic Defects in Metals. Springer, 1991.

[39] E.H. Megchiche, C. Mijoule, and M. Amarouche. First principles calculations of vacancy-vacancy interactions in nickel: thermal expansion effects. Journal of Physics: Condensed Matter, 22(48):485-502, 2010.

[40] J.T. Busby, G.S. Was, and E.A. Kenik. Isolating the effect of radiationinduced segregation in irradiation-assisted stress corrosion cracking of austenitic stainless steels. Journal of Nuclear Materials, 302(1):20-40, apr 2002.

[41] H.K. Zhang, Z. Yao, M.R. Daymond, and M.A. Kirk. Elevated temperature irradiation damage in CANDU spacer material Inconel X-750. Journal of Nuclear Materials, 445(1-3):227-234, 2014.

[42] N. Azam, L. LeNaour, and J. Delaplace. Évolution de la densité de dislocations dans des aciers austénitiques du type $316 \mathrm{~L}$ irradiés par des ions $\mathrm{Ni}+$ de moyenne energie. Journal of Nuclear Materials, 49:197-208, 1973.

[43] H.R. Brager and J.L. Straalsund. Defect Development in Neutron Irradiated Type 316 Stainless Steel. Journal of Nuclear Materials, 46:134-158, 1973.

[44] F.A. Garner. Evolution of microstructure in face-centered cubic metals during irradiation. Journal of Nuclear Materials, 205:98-117, 1993.

[45] B.H. Sencer, G.S. Was, M. Sagisaka, Y. Isobe, G.M. Bond, and F.A. Garner. Proton irradiation emulation of PWR neutron damage microstructures in solution annealed 304 and cold-worked 316 stainless steels. Journal of Nuclear Materials, 323(1):18-28, 2003.

[46] A. Etienne, M. Hernández-Mayoral, C. Genevois, B. Radiguet, and P. Pareige. Dislocation loop evolution under ion irradiation in austenitic stainless steels. Journal of Nuclear Materials, 400(1):56-63, 2010.

[47] J.D. Tucker, R. Najafabadi, T.R. Allen, and D. Morgan. Ab initio-based diffusion theory and tracer diffusion in $\mathrm{Ni}-\mathrm{Cr}$ and $\mathrm{Ni}-\mathrm{Fe}$ alloys. Journal of Nuclear Materials, 405(3):216-234, oct 2010.

[48] J.F. Stubbins and F.A. Garner. Swelling and microstructure of high purity nickel irradiated with fast neutrons in EBR-II. Journal of Nuclear Materials, 191-194:1295-1299, 1992.

[49] T. R. Allen, J. I. Cole, C. L. Trybus, D. L. Porter, H. Tsai, F.A. Garner, E.A. Kenik, T. Yoshitake, and J. Ohta. The effect of dose rate on the response of austenitic stainless steels to neutron radiation. Journal of Nuclear Materials, 348(1-2):148-164, 2006. 